\title{
Team-based Simulations among Teacher Trainees: Ethical Dilemmas and Psychological Empowerment in School Bullying Cases
}

\author{
Yifat Davidoff ${ }^{1}$, Orly Shapira-Lishchinsky ${ }^{2}$ \\ School of Education, Department of Educational Leadership and Policy \\ Bar-Ilan University, Israel
}

\begin{abstract}
This study explores the effect of group simulations on teacher-trainees in comparison to case study groups in dealing with ethical dilemmas in school bullying. Simulations (role-playing) are defined as models of reality that provide learners with the opportunity to play the roles of different figures involved in situations under discussion. When faced with similar events in real-life experiences, teacher-trainees can extract from memory information and strategies learned from these simulations as if they really occurred.

The population of the study comprised 90 teachertrainees in their third year of majoring in primary school education. Two experimental groups - a teambased simulation (TBS) and a case-study group had a meeting of 3.5 hours each month during 10-month period (10 meetings in total), in which they analyzed the same bullying scenarios that were based on the participants' real-life experiences. While both experimental groups discussed ethical dilemmas that arose in the scenarios, the TBS group engaged in roleplaying simulations and the case study group did not use role-playing simulations. An additional control group only completed the same psychological empowerment questionnaires filled out by both other experimental groups.

The results, based on a mixed-methods approach, showed that the simulation group demonstrated significantly higher psychological empowerment in selfconfidence and decision-making when dealing with ethical dilemmas around bullying at school.

This study offers an innovative approach for training educators to confront bullying-related ethical dilemmas in daily school life in an active and empowering way.
\end{abstract}

\section{Introduction}

Bullying is a worldwide scourge in schools that negatively impacts educational activities. It includes antisocial behaviors with physical, emotional, social and academic consequences that cause many students to perceive school as an unsafe environment [10], [18]. According to large-scale OECD social surveys and educational studies, bullying in schools is a dangerous problem, whose consequences are serious enough to threaten the future of the global society [10].

Many teachers feel helpless in dealing with bullyingrelated ethical dilemmas, and have little or no support from the system. They report a desperate need for tools to cope with the problem [11]. However, studies show that although the acute need is projected from the field,

most teachers have not received any form of bullying prevention training as teacher trainees [25].

This study's goal was to examine the effect of simulations (role-playing) on the psychological empowerment of teacher trainees, in comparison to discussing case studies while confronting bullyingrelated ethical dilemmas based on school scenarios. Psychological empowerment is the relationship between individuals' beliefs, values and standards, and their professional functioning in tasks. Highly psychologically empowered teachers tend to feel that they have the skills and knowledge necessary to improve their actions and solve complex issues effectively [20], [27].

The choice of using simulations for this study is based on previous studies indicating that simulations entail the rehearsal of teaching skills, leading to a qualitative experiential and applicative transfer of operative memory [7], [20], [29].

Simulations are a source from which internalized insights and strategies can be accessed when similar events occur in real time. Moreover, simulations represent an enjoyable and experiential means of study that motivates engaged learning. They promote a sense of psychological empowerment in coping with dilemmas in the workplace and encourage cooperation and reflective, operative group thinking [20], [29].

Therefore, we were interested in studying how the use of team-based-simulations (TBS) in comparison to case-study training affects the teacher trainees' psychological empowerment when confronting bullying-related ethical dilemmas at school. We additionally used a control group that did not participate in the intervention process (simulation/case study groups) and only filled out the same psychological empowerment questionnaires at similar points of time as the experimental groups.

In line with the above, we discuss the following research questions:

(a) What are the characteristics of the ethical dilemmas raised by the two experimental groups (the TBS group and the case-study group)?

(b) What psychological empowerment changes occur in the experimental groups and the control group during the study?

The sections below provides an overview of the following subjects: bullying in schools, ethical dilemmas in dealing with bullying, training by group simulations and case studies, and finally, psychological empowerment when dealing with school bullying. All these subjects are relevant to the main goal of the study, 
exploring the effect of group simulations on teachertrainees in comparison to case studies in dealing with ethical dilemmas of school bullying.

\section{Theoretical background}

\subsection{Bullying in schools and its consequences}

According to research, "school bullying" refers to any directed behavior intended to emotionally or physically harm other people, their property, or school property. It is characterized by hostile intent and repetition, including physical and verbal violence, and social bullying [13]. Bullied students experience anxiety, lack of protection, dissatisfaction with life, and high levels of depression, including suicidal thoughts. Therefore, school bullying is a problem that threatens the education system [9].

\subsection{Teachers' perceptions of their training to deal with bullying}

Various studies show that most teachers are disappointed by the lack of attention that dealing with bullying receives in teacher training curricula. In their view, bullying is considered a low-priority item compared to teaching theoretical content and absorbing academic teaching-learning strategies [16], [25], [26].

Teacher trainees feel professionally inadequate and powerless when dealing with ethical dilemmas related to bullying scenarios, and they have limited means of action [22], [25]. In resolving ethical dilemmas concerning bullying and their professional inadequacy, trainees tend to depend on colleagues' help [25]. These findings led us to investigate the concept of psychological empowerment to help deal with ethical dilemmas related to school bullying.

Studies indicate that to adequately train both teachers and teacher trainees, practice is needed along with applying a variety of alternative coping methods for bullying in a supportive environment. This includes opportunities to exchange experiences, ideas and opinions about the difficulties encountered [5], [6], [16], [25].

\subsection{Ethical dilemmas in dealing with bullying}

Ethical dilemmas in bullying are described as complex situations that usually entail ethical conflicts. Society expects teachers to be guided by ethical principles in dealing with bullying. Teachers are perceived as professionals who help shape society and therefore, should be capable of making ethical decisions for the general good and for shaping the coming generations of citizens [1], [8].
Studies indicate that challenging teachers with ethical dilemmas helps them develop emotionally, morally and operatively. Emotionally, dealing with ethical dilemmas arouses feelings of empathy, the recognition of feelings of others and their existential state, as well as concerns for assuring their dignity and welfare [1]. Morally, by engaging in such dilemmas, teachers elevate the importance of basic human values, egalitarianism and moral judgment based on concepts of universal human rights. Operatively, studies show that familiarity with a variety of ethical dilemmas and ethical principles assist teachers in constructing a professional and efficient toolbox [1], [8].

\subsection{Group simulation training}

Simulations are defined as models of reality that include elements of play involving thinking and acting [7], [29]. The simulation process includes two stages: the internal and external stages. (a) The internal stage is a process of self-examination which creates an internal representation in the brain of similar situations. This arouses motivational processes that include internalization in long-term memory as well as thinking and planning for the future. (b) The external stage entails processes of expectation and prediction, which constitute possible practical projections for the brain to utilize in future relevantly similar situations [4]. According to previous studies, simulations focus on the main aspects that affect the outcomes of the event. These effective methods remain in the participants' memory when being exposed to future scenarios [4], [29].

Simulations provide learners with the opportunity to "step into the shoes" of figures involved in the situations under discussion. When faced with similar events in real life, individuals can extract information stored in their memory as if from a library of past experiences. These scenarios may serve to neutralise cognitive disturbances caused by the element of surprise and unfamiliarity, which may evince discomfort and overprotectiveness [4], [7].

Previous studies indicate that simulations increase psychological empowerment when learners prepare for implementation. They also develop emotional abilities, such as empathy [7], [5]. Simulations also increase the brain's ability to imagine possible future real-life scenarios [7]. Moreover, through team-based simulations, participants develop a sense of mutual assistance, and become willing to share their difficulties and weaknesses with other team members [5].

Studies that support videotaping the simulation workshops, suggest that learning occurs not only when engaged in role-playing, but continues and deepens during the debriefing stage. In this second stage, the participants analyze and discuss the events by watching 
videos of the role-playing. Additionally, the use of videotaping improves practical thinking about pedagogical strategies and increases participants' psychological empowerment [6], [23].

\subsection{Training by case studies}

The case study approach focuses on a single or a small number of cases, to shed light on a larger number of similar cases. Using case studies, learners analyze many similar cases to consciously shift the focus from specific cases to a general principle-based thinking structure [17]

In teacher training, the case study approach is a common method used for analyzing types of daily classroom events that require elucidation. The process includes confronting complex situations from the real world, gathering relevant information about its components and analysing this information considering existing professional knowledge [21].

Part of the analysis process includes discussing various hypothetical solutions that are raised, and their possible short and long-term effects. According to professional case study literature, the greater the number of case studies, and the closer they are to the subject, the more possible it is to make practical projections from specific cases to reality [17], [21].

The case study approach has been shown to contribute to a wider trainee awareness of effective strategic management of bullying events in schools. Discussions within the process also contribute to heightening reflective-insightful discourse between the student groups. This experience can increase their psychological empowerment [6].

\subsection{Psychological empowerment of educators in dealing with bullying}

Psychological empowerment is defined as "intrinsic motivation reflecting a sense of self-control in relation to one's work and an active involvement with one's work role" [24]. Psychological empowerment in performing tasks is the relationship between individuals beliefs, values and standards, and their professional functioning. Teachers with high psychological empowerment tend to feel that they have the skills and knowledge necessary to improve their actions and solve problems effectively.

Generally, they see themselves as efficacious, free to make decisions, influential in terms of applying strategies and empowered by the organization to introduce change. Greater psychological empowerment in teachers corresponds to greater commitments to work and better performances in dealing with student bullying [20], [24], [27].
Various factors facilitate higher teacher empowerment: a climate of sharing and inclusion, teamwork, good communication with superiors, clearly defined organizational positions and roles, decentralized management which enables them to deal with ethical events including student bullying, and active decisionmaking pertaining to their work [20], [27].

\section{Method}

\subsection{Participants and ethical guidelines}

The study sample included students at a teachers' training college, located in central Israel, who agreed to participate in the study. The sample included 90 teacher-trainees: 88 women and two men, between the ages of 22 and 38 years old in their third year of training, majoring in both primary school teaching and their area of specialization (e.g., mathematics, history, sciences, literature, language or English). The sample's gender gap is not much larger than the OECD's gap: approximately $90 \%$ women and $10 \%$ men in primary educational studies [12].

The study process was conducted according to the rules of the Ethical Principles of Psychologists and Code of Conduct (2002). Participants received information about the aims and procedures of the study. The workshops were conducted outside college course curriculum hours, and the participants received no grades or credit points for the study. Their motivation to participate in the study was their desire to engage in a unique learning experience and to acquire tools for effectively dealing with bullying in school.

The participants were asked to sign a consent form to participate in the study. They were promised anonymity and permission to leave the study at any point.

\subsection{Division of the sample into three groups}

The 90 teacher trainees participating in the study were divided randomly into three groups of 30 participants each: two experimental groups and a control group. Participants of the experimental groups were randomly divided into three groups of ten participants each.

The teacher trainees in the TBS groups engaged in role-playing simulations, combined with reflective discussions. They analyzed and resolved ethical dilemmas that they identified while reviewing scenarios related to bullying. The case study groups went through the same analytical processes without the role-playing simulation procedure. The mentors of the two experimental groups had a Master's degree in mentoring and over six years of experience mentoring groups. 
The control group did not have any intervention at all. They served as a baseline comparison group to determine what changes, if any, occurred in the personal attitudes of the experimental groups. This was examined using psychological empowerment questionnaires identical to those completed by the experimental groups at the same time-points.

The researcher's role was to advise the mentors of the two experimental groups, to inform the teacher-trainees about the process, and to organize the pedagogical process for these groups.

\subsection{Research tools}

3.3.1. Bullying scenarios. The teacher trainees in the experimental groups were first asked to write a case of bullying that they had encountered which entailed ethical dilemmas. This step was requested because previous studies have shown that scenarios resembling real-life situations are more effective [4], [7].

Six representatives from each experimental group (twelve in total) randomly selected ten bullying scenarios to be used in the study. The choice of scenarios was varied to ensure that they represented situations that the participants would very likely encounter as teachers.

\subsubsection{The psychological empowerment} questionnaire. We used Sprietzer's questionnaire for the quantitative analyses of the teacher-trainees' psychological empowerment. This questionnaire examines how well-equipped individuals perceive themselves to be for successfully functioning at work. The overall reliability of the original questionnaire is $a$ $=.84$. [20], [27].

The original statements were adapted to address participants' attitudes about their ability to deal with school bullying-related ethical dilemmas. The questionnaire relates to two main dimensions of psychological empowerment relevant to the present study:

a. Self-confidence and decision-making - Individuals' perceptions of possessing the necessary tools to choose, initiate and implement programs, based on assessing and making decisions in bullying-related situations in school. For example, items included: "I am confident about my ability to do my job related to dealing with bullying" ( $a=.76)$.

b. Meaning of work in relation of dealing with bullying Individuals' perceptions of the correspondence between the importance of their work in dealing with bullying and their ideas and standards, e.g., "The work I do related to bullying in school is very important to me" $(a=.80)$.
We used a five-point Likert response scale, ranges from 1 (not confident at all) to 5 (very confident). The overall reliability of the questionnaire was $a=.78$.

3.3.3. Group reflective debriefing reports. During the workshops' reflective discussions, each subgroup of the two experimental groups was asked to fill out group reflective debriefing reports in which they described the ethical dilemmas and the different possible solutions that were raised by the members for the dilemmas raised.

\subsection{The intervention procedure}

3.4.1. The team-based simulation (TBS) group. The participants in the TBS group attended ten meetings of 3.5 hours each. The meetings were held once every month over ten months in total. At the first meeting, the students completed psychological empowerment questionnaires and engaged in group discussions of bullying ethical dilemmas.

Each of the following workshops included a full class discourse about bullying as it pertained to the scenario being analyzed at that meeting. Following the discourse, the teacher-trainees worked in permanent groups of ten participants each. There, they delved more deeply into the case and the backgrounds of those involved. They initially dealt with the ethical dilemmas that arose from the scenario. They then chose and roleplayed 2-3 of the solutions that they raised to these bullying-related ethical dilemmas. The simulations were video recorded and then uploaded to a shared drive for all participants to access and watch.

While some team members simulated alternative solutions in a separate room that imitates a real-life discourse environment (to give the participants an atmosphere and experience that matches the one they will encounter in a similar situation in reality), the rest of the group observed the filmed simulations live on a screen, noting moments they perceived as influential and meaningful. They then all watched these interactions on video and reflected on the different responses. In the end of each meeting, they summarized their conclusions in the group reflective debriefing reports.

To summarize, each teacher-trainee participated in 10 meetings of 3.5 hours each (35 hours in total) throughout ten months in ten monthly meetings and actively participated in 2 to 3 simulations during each meeting.

A year after the conclusion of the intervention procedure, the students again completed the same psychological empowerment questionnaire they had filled out before beginning the intervention. The intention was to examine what changes, if any, had occurred in their perceptions of various aspects of 
psychological empowerment over time as a result of the simulation intervention.

3.4.2. The case study group. The procedure for the case study group was similar to the TBS group. The only difference was that this group did not engage in role-playing simulations.

3.4.3. The control group. The 30 teacher-trainees in the control group completed both psychological empowerment questionnaires about dealing with school bullying, and on the same dates as the experiential groups did. However, this group did not undergo any interventions.

\subsection{Data Analysis}

Data analysis was longitudinal research based. The results are based on 60 group reflective the debriefing reports from the two experimental groups (3 sub-groups in each experimental group $X 10$ meetings in each experimental group $X 2$ experimental groups $=60$ ), 73 role playing simulations (each sub-group conducted several role playing simulations in every meeting), and 180 psychological empowerment questionnaires filled out by the experimental groups and the control group during two time-points: 90 questionnaires before the intervention process and 90 questionnaires a year after the end of this process.

3.5.1. Qualitative analysis. The qualitative methodology included transcribing of the simulations done by the TBS group and the analysis of 60 group reflective debriefing reports from the two experimental groups (30 from each group). The ethical dilemmas raised by the participants regarding the bullying events were analyzed by means of free coding [14]. This was determined by the repetition of basic concepts, statements and phrases and overt behaviors of the participants. The data were initially analyzed separately by each author. In the second stage, the authors met and reached an agreement about the findings and their division into categories, sub-categories and dimensions.

3.5.2. Quantitative analysis. The quantitative methodology focused on deductive statistics based on data processing of the psychological empowerment questionnaire regarding the perceived ability to deal with bullying in schools on two dimensions: (a) Selfconfidence and decision-making and (b) Meaning of work in relation to dealing with bullying.

The data analysis was based on a $3 \times 2$ study design, in which 3 represented the three research groups (TBS, case studies, control), and 2 represented the two time points in which the questionnaire was completed, as previously mentioned. This procedure was used to ascertain if the intervention affected the students' perceptions a year after the end of the intervention.

Analysis of the quantitative data included: (a) exploratory analysis to identify questionnaire variables and dimensions; (b) analysis of two-factor variance repeated measures (ANOVA between-subjects factor); (c) post hoc changes in questionnaire values over the study period; (d) correlations between study variables.

\section{Results}

\subsection{The main ethical dilemmas cited by the experimental groups}

Four central ethical dilemmas appeared in the written summaries of both experimental groups and in the simulations:

(1) Loyalty to the educational agenda versus parental involvement. For example, based on the TBS group's reflective debriefing reports in a case of parents' complaints against a homeroom teacher concerning their ostracized child who was being physically bullied by classmates:

"We know that this mother is very assertive and overprotective, in ways that are not always situation appropriate... what do we do when a parent expresses opposition to a teacher's professional decisions and accuses her of discriminating against their child? We cannot give in on our educational and professional ideals..."

(2) Protecting student victims versus the desire to educate the bully. For example, based on a simulated conversation by the TBS group around a case of verbal and physical bullying of an Ethiopian child, using racial epithets - Counsellor:

"We must be careful not to cause unnecessary harm to the child who used racist epithets and think of how to emphasise the general social value of accepting others...."

Teacher A: "But his behavior was racist!"

Teacher B: "Maybe we should recruit the bully for a positive action. Let him lead an activity about accepting others who are different."

Counsellor: "Good idea ... First, the teacher will lead the activity, and after the student undergoes a process, he can lead a similar activity in the other classes with the teacher's supervision."

(3) Loyalty to professional conduct versus concern for professional status. For example, based on the reflective debriefing reports of both experimental groups around a case of online bullying: 
"We don't know what our obligation is... We have no idea if there are specific rules about our responsibility..."

"Parents can claim why are you intervening? It's not your business; it happened after school hours...We think it is right to intervene... It doesn't seem right to limit our actions to those that affect the school and only during work hours..."

(4) Loyalty to professional values versus loyalty among team members. For example, based on the case-study group's reflective debriefing reports around a teacher's inability to handle bullying in the lesson:

"On the one hand, we don't want to upset relations with a colleague. On the other hand, it's very hard for us to stand by and see such inappropriate dealings toward a student and not report it to the management...".

Conceptual similarities were found among the experimental groups (TBS, case study) in terms of the main ethical dilemmas highlighted by the participants. Both groups proposed dilemmas that could be categorized into four domains: teacher-student relations; teacher-parent relations; teacher-peer relations and teacher-management relations.

Figure 1 presents explanations and examples of the dilemmas and their dimensions in the findings, reflecting a multifaceted structure of ethical dilemmas.

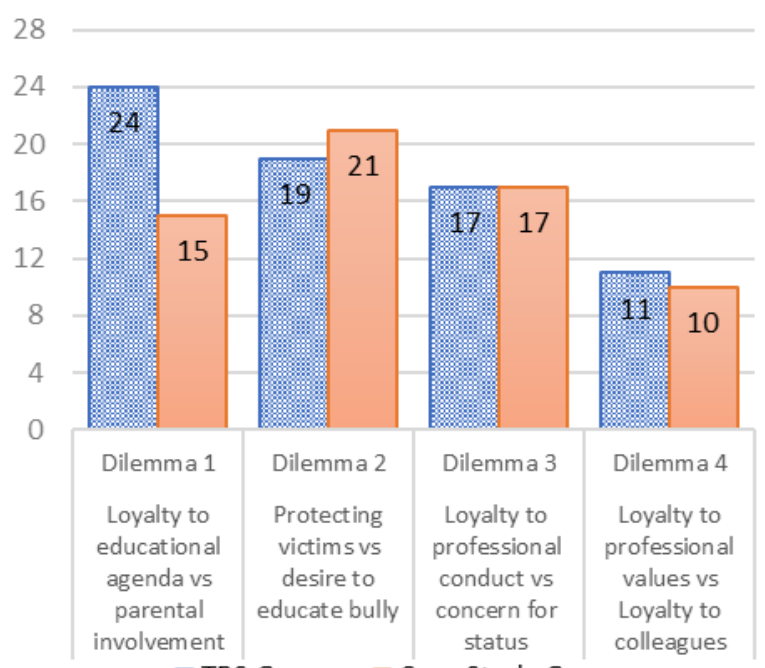

圆TBS Group $\square$ Case Study Group

Figure 1. Main ethical dilemmas of the experiential groups

\subsection{Results of the quantitative analysis}

A 3x2 (research groups: TBS, case study, and control group; time - before and one year after the intervention) ANOVA with repeated measures on the last variables was used to analyze the data. The means and standard deviations of 'self-confidence and decision-making in relation to dealing with bullying' is summarized in Table 1. The means and standard deviations of 'meaning of work in relation to dealing with bullying' is summarized in Table 2 .

4.2.1. Self-confidence and decision-making. A significant interaction effect (see Figure 2) between group type and time of measurement was found $[\mathrm{F}(2,174)=10.64$, MSE (mean square error) $=.341, \mathrm{p}$ $\left.<.001, \eta \mathrm{p}^{2}=.21\right]$.

Table 1. Means for 'self-confidence and decision making' in relation to dealing with bullying'

\begin{tabular}{|c|c|c|c|}
\hline \multirow[t]{2}{*}{ Groups } & \multirow[b]{2}{*}{$\mathrm{N}$} & \multicolumn{2}{|c|}{$\begin{array}{l}\text { Self Confidence \& } \\
\text { Decision Making }\end{array}$} \\
\hline & & Before & After \\
\hline TBS & 30 & $\begin{array}{l}3.59 \\
(0.57)\end{array}$ & $\begin{array}{l}3.98 \\
(0.43)\end{array}$ \\
\hline Case Study & 30 & $\begin{array}{l}3.57 \\
(0.80)\end{array}$ & $\begin{array}{l}2.98 \\
(0.48)\end{array}$ \\
\hline Control & 30 & $\begin{array}{l}3.58 \\
(0.58)\end{array}$ & $\begin{array}{l}3.58 \\
(0.57)\end{array}$ \\
\hline
\end{tabular}

Note: The numbers in parenthesis are standard deviations

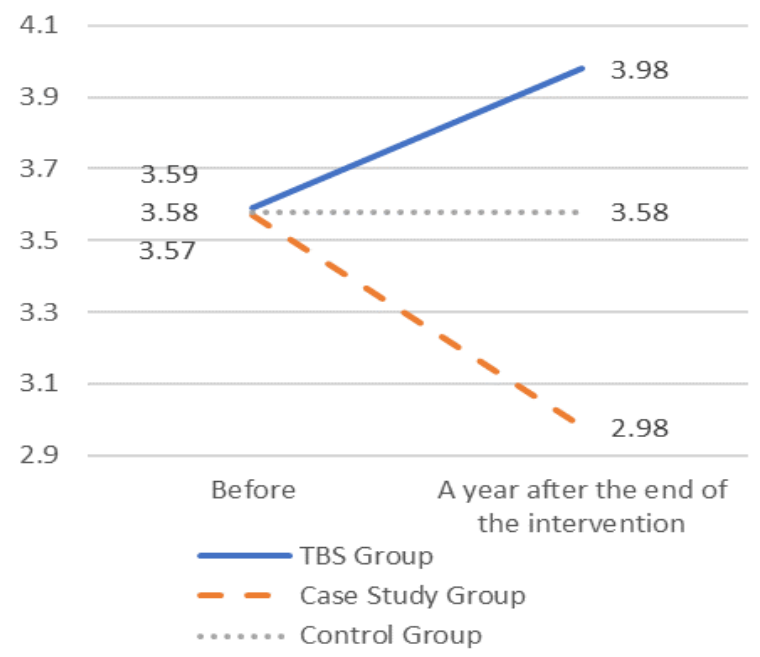

Figure 2. The interaction between time and 'selfconfidence and decision making 
In other words, $21 \%$ of the variance of 'self-confidence and decision-making' is explained by the interaction. Simple effect tests indicated that over time, in the simulation group, 'self-confidence and decision-making' increased significantly [from $\mathrm{M}=3.59, \mathrm{SD}=.57$ to $\mathrm{M}=3.98, \mathrm{SD}=.43 ; \mathrm{F}(1,174)=6.46, \mathrm{MSE}=.341, \mathrm{p}<.01$, $\left.\eta p^{2}=.26\right]$. That is, $26 \%$ of the variance of 'selfconfidence and decision-making' is explained by the interaction. However, the case study group demonstrated a significant decrease in self-confidence and decision-making [from $\mathrm{M}=3.57, \mathrm{SD}=.80$ to $(\mathrm{M}=2.98, \mathrm{SD}=.48)$. No significant difference was found for the control group over time ( $\mathrm{F}>1, \mathrm{~ns}$.).

4.2.2. Meaning of work in dealing with bullying. A significant interaction effect (see Figure 3) between group type and time measurement was found $[\mathrm{F}(2,174)=4.25$, mean square error $(\mathrm{MSE})=.348$, p $\left.<.01, \eta \mathrm{p}^{2}=.25\right]$. In other words, $25 \%$ of the variance of 'meaning of work' is explained by the interaction. Simple effect tests indicated that the case study group significantly decreased over time in their perception of 'meaning of work' in relation to dealing with bullying [from $\mathrm{M}=4.42, \mathrm{SD}=.53$ to $(\mathrm{M}=4.07, \mathrm{SD}=.63)$, $\left.\mathrm{F}(1,174)=5.442, \mathrm{MSE}=.341, \mathrm{p}<.05, \eta \mathrm{p}^{2}=.23\right]$. That is, $23 \%$ of the variance of 'meaning of work' is explained by the interaction. No significant changes over time were found for the simulation group or for the control group $(\mathrm{F}>1, \mathrm{~ns}$.$) .$

Table 2. Means for 'meaning of work in relation to dealing with bullying'

\begin{tabular}{|c|c|c|c|}
\hline \multirow[t]{2}{*}{ Groups } & & \multicolumn{2}{|c|}{ Meaning of Work } \\
\hline & $\mathrm{N}$ & Before & After \\
\hline TBS & 30 & $\begin{array}{l}4.57 \\
(0.59)\end{array}$ & $\begin{array}{l}4.44 \\
(0.51)\end{array}$ \\
\hline Case Study & 30 & $\begin{array}{l}4.42 \\
(0.53)\end{array}$ & $\begin{array}{l}4.07 \\
(0.63)\end{array}$ \\
\hline Control & 30 & $\begin{array}{l}4.47 \\
(0.73)\end{array}$ & $\begin{array}{l}4.73 \\
(0.52)\end{array}$ \\
\hline
\end{tabular}

Note: The numbers in parenthesis are standard deviations

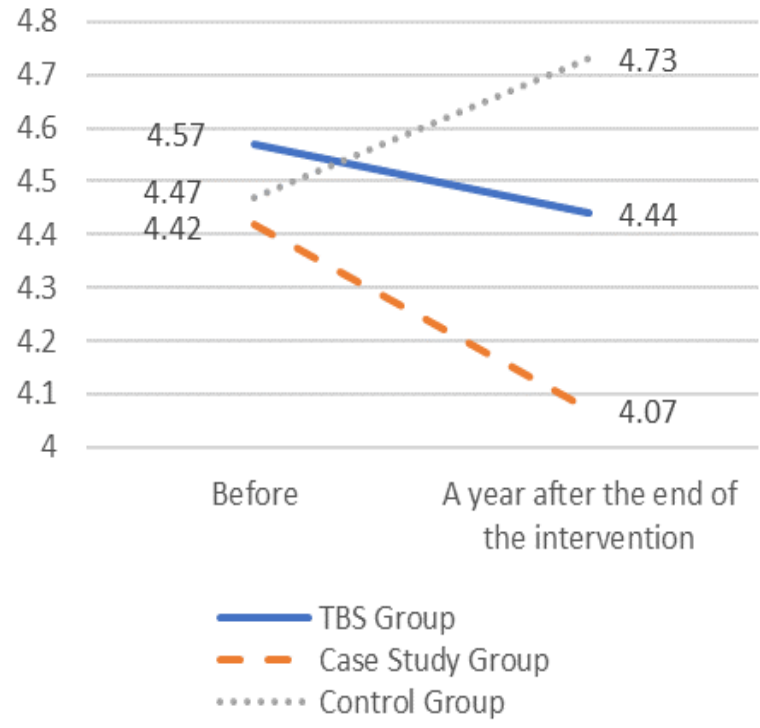

Figure 3. The interaction between time and 'meaning of work' in relation to dealing with bullying'

\section{Discussion}

This study explored the psychological empowerment of teacher trainees following the use of simulations and case study training methods to deal with bullying events that raise ethical dilemmas in school. Careful examination of the scientific and professional literature in these domains revealed that this is the first study to test TBS as a training model for teacher-trainees to deal with school bullying. Despite the high incidence of school bullying, most teachers and teacher trainees have not participated in bullying prevention training programs [5]. Furthermore, there is almost no research on teachers' psychological empowerment in dealing with bullying.

The findings of the study confirm the relevancy of conducting simulation workshops similar to those proposed in the present study. These simulations have the potential to provide psychological empowerment that enhances the self-confidence needed to make insightful decisions.

The findings considering the first research question, which focused on the characteristics of the ethical dilemmas raised by the two experimental groups, showed conceptual similarities among the experimental groups. Both groups proposed dilemmas that could be categorized into four domains: teacher-student relations; teacher-parent relations; teacher-peer and teachermanagement relations. These domains are similar to those noted in studies dealing with ethical dilemmas that engage educators [8].

The ethical dilemmas raised by the teacher-trainees around teacher-student relations focused on the participants' perceptions about the educational 
processes that they are obligated to follow with all students involved in bullying. Similar to studies that have explored appropriate ways to deal with bullying at school [28], the participants in both experimental groups held a caring approach to social values against bullying. According to their perceptions, both sides need support and inclusion. This viewpoint corresponds to findings in previous studies of school bullying that advocate a caring approach toward both bullies and their victims [25].

For those who bully, educational efforts should be made to reveal the motivations of their actions and to learn how their negative behaviors can be eliminated or prevented in the future. For those who are bullied, efforts should be focused on empowering their straights and creating a positive cooperation between both parties [13]. The teacher-trainees understood that without an educational process, bullies tend to become more threatening and dangerous over time to those around them and the victims tend to suffer from continual reduction in their self-esteem and social skills. These feelings elicited the insight that in sensitive situations, the best way to obtain positive results is through calm, pleasant and inclusive discourse, with no accusations or punishment. Such discussions should also clearly define the boundaries for physical and emotional safety and promote cooperation [9].

The ethical dilemmas dealing with teacher-parent relations focused on staff adherence to their educational path versus possible objections from parents. Analysis of the findings shows that the teacher trainees perceive such relations as highly complex, confusing and frustrating. The main cause of these negative feelings is a lack of knowledge about the boundaries of their responsibility and uncertainty about the rules of engagement when dealing with bullying. The teacher trainees view some teacher-parent relations as clashes of values that require creative, structured thinking leading to a fruitful cooperation.

In their summary reports, the trainees demonstrated their understanding that parents instinctively protect their children. However, teachers must stand strong against parents' objections and create a learning environment free of bullying. According to the teacher trainees' perceptions, parents should not call into question the teacher's authority. This approach is supported by other studies, which argue that parents are an essential resource that can provide teachers with assistance and support [15].

Another central ethical dilemma related to dealing with school bullying was teacher loyalty to professional values versus loyalty among team members. The study findings indicate that teacher trainees perceive such situations as difficult, embarrassing and potentially harmful to interpersonal staff relations. This situation is additionally potentially harmful for their future employment opportunities, especially when the problem involves a powerful senior colleague. Furthermore, they fear being perceived by other peers as "informers" which would undermine their social and personal status in the school. This could happen even in cases where reporting improper behavior by a peer to management contributes to the students' welfare.

Previous studies [5] indicate that teacher trainees believe in the importance of standing up for their colleagues, but not at the expense of their students' wellbeing. In our study, despite their fear of personal consequences, most of the respondents preferred to report peer problems to the administration, if they were unable to deal with the problems themselves.

As part of dealing with complex issues and ethical dilemmas that have also been discussed in previous studies [9], our study found that the teacher-trainees believe that the school administration must provide teachers with support and instruction. They believe that educational leadership supporting teachers encourages reflective thinking in teams and provides guidelines, benefits the school and increases the teachers' feelings of self-competence when dealing with bullying.

This study also focused on comparing the effects of TBS to case study training methods on the participants' psychological empowerment to deal with bullyingrelated ethical dilemmas in school. As expected, both groups reported that handling bullying events was difficult. For most of them, this was their first exposure to discussions and dealings with bullying scenarios. Moreover, they were not in any position to influence the school or the classes in which they practice-taught. Therefore, it was expected that in an encounter with the bullying scenarios, both experimental groups would raise concerns about the extent of their competence to deal with such situations in the future.

The second research question deals with the changes occurring in the psychological empowerment of the experimental groups and the control group during the study. As noted, the two main dimensions of psychological empowerment that were examined were 'self-confidence and decision-making' and 'meaning of work'. The first dimension, self-confidence and decision-making, referred to the individuals' feelings of having a choice whether to initiate and direct actions based on informed decisions as well as the tools to decide for themselves how to act with confidence [20], [27].

The study findings indicate a significant increase in the TBS group and a significant decline in the case study group in this dimension. These findings are consistent with previous studies [19], [27] which show that active learning enhance participants' capability to deal with ethical dilemmas in daily functioning. Thus, participants gain greater self-confidence and feelings of 
control in their decision-making and consequently have greater self-confidence and feelings of control in their environment.

In contrast, we found that when teacher trainees were only exposed to bullying situations without participating in the role-playing and the video-based analysis, feelings of insecurity and lack of control increased. Also, their ability to make independent decisions in such situations declined. These findings led us to the understanding that training processes for dealing with school bullying should be interactive and highly participatory and should not only include case study analysis as more commonly done [29].

The second dimension, 'meaning of work', refers to perceptions of correspondence between the importance of the aims of their work (dealing with bullying), and their personal ideals and standards as employees. The findings for this dimension showed that while the TBS groups maintained its perception over time, the case study groups demonstrated a significant decrease concerning this aspect over time. The explanation for this result is similar to the explanation concerning what occurred in terms of self-confidence and decisionmaking, regarding the frustration that members of the case study group felt when exposed to the bullying scenarios without the buffering effect of simulations. Thus, it can be said that despite the difficulty entailed in dealing with bullying-related dilemmas in school, the simulation methodology helped the TBS group to maintain their feelings of the meaningfulness of the process.

To summarize, the similarity between the ethical dilemmas raised by the two experimental groups, compared with the significant difference in their psychological empowerment to cope with bullying in school, shows that participation in simulations does not alter the nature of what constitutes an ethical dilemma. However, it does affect the individuals' perceptions of their ability to deal with such ethical dilemmas. This interesting finding demonstrates the importance of using simulations as a tool for dealing with ethical dilemmas related to bullying.

According to the trainees who participated in the simulations, stepping into the shoes' of the various figures in the simulations enabled them to experience a range of emotions such as insult, physical fear and emotional anxiety, both from the viewpoint of the bullies and of the bullied.

Our study emphasizes that when using simulations, participants maintain a consistent understanding of the substantive ethical dilemmas, while at the same time, their perceptions of self-empowerment are enhanced even a year after the end of the intervention. This enhancement will ultimately motivate them to feel safe and be more effective in dealing with bullying, hence actually making these teachers more competent.

\section{Conclusions}

This study is the first of its kind to explore how TBS and case study interactions can influence, even a year after the end of the intervention, teacher-trainees' psychological empowerment and their perceptions of their ability to deal with bullying-related ethical dilemmas in schools.

The quantitative findings of the study provide important conclusions about the contribution of the use of simulations to the psychological empowerment of teacher-trainees in terms of their self-confidence and decision-making in dealing with real bullying situations. According to previous research, the rise in psychological empowerment has a positive influence on workers' operational capabilities and contributes to the organization by raising workers' efficiency, freedom to make decisions, and influence regarding applying strategies. It also enhances their commitment to work.

Simulations may also help reduce teacher trainees' feelings of helplessness in various bullying situations encountered in their practice. In contrast, the case study training had the opposite result. There was a significant decline in psychological empowerment. The important conclusion is that to greatly reduce teachers' and teacher-trainees' frustration when dealing with bullying, training procedures should employ mediating experiential methodologies, such as simulations, and avoid solely depending on the traditional case studies approach. This approach will lead to less frustration and greater self-confidence.

\section{Limitations and additional research}

One limitation of this study is that the research and workshops were directed to teacher trainees. Therefore, it is recommended for future studies to examine how simulations for teachers affect school students over time, as well as the level of bullying in school. It will also be advantageous to conduct a study on teachers and not trainees and see the impact of TBS training on their self-efficacy to deal with bullying at school and on the level of bullying at school.

An additional limitation is that this study focused on a population of students training in teaching in elementary schools. In order to generalize the findings and learn more broadly about the effects of simulations on learning, it is recommended to conduct similar studies among other student populations (for example high schools / special education) and other disciplines (for example - engineering students/entrepreneurs). Expanding this research to other disciplines is extremely important since according previous studies (e.g., [2]), there is a growing need for students in different disciplines to include experiential learning in their 
qualification processes in universities to better prepare them in dealing with ethical dilemmas and challenges they are likely encounter in real life.

\section{References}

[1] Aloni, N. (2013). Empowering Dialogues in Humanistic Education. Educational Philosophy and Theory, 45, 1067 1081.

[2] Arias, E., Barba-Sánchez, V., Carrión, C, \& Casado, R. (2018). Enhancing Entrepreneurship Education in a Master's Degree in Computer Engineering: A Project-Based Learning Approach. Administrative Science, 8(4), 58. DOI: 10.3390/ admsci8040058

[3] Anderson, P. H., \& Lawton, L. (2009). Business simulations and cognitive learning: Developments, desires and future directions. Simulations \& Gaming, 40(2), 193-216.

[4] Atance, C. M., \& Hanson, L. K. (2011). Making predictions: A Developmental Perspective. In M. Bar (Ed.), Prediction in the brain (pp. 311-324). New York, NY: Oxford University Press.

[5] Author (2013).

[6] Author (2016).

[7] Bar, M. (Ed.). (2011). Prediction in the brain: Using our past to generate our future. New York, NY: Oxford University Press.

[8] Barrett, D. E., Casey, J. E., Visser, R. D., \& Kathy, N. H. (2012). How do teachers make Judgments about ethical and unethical behaviors? Toward the development of a code of conduct for teachers, Teaching and Teacher Education, 28(6), 890-898.

[9] Burger, C., Strohmeier, D., Spröber, N., Bauman S., \& Rigby, K (2015). How teachers respond to school bullying: An examination of self-reported intervention strategy use, moderator effects, and concurrent use of multiple strategies. Teaching and Teacher Education, 51, 191-202.

[10] CDC - Center for Disease Control and Prevention (2017). Youth violence. Retrieved from https://www.cdc.gov/ violenceprevention/youthviolence/index.html.

[11] Dedousis-Wallace, A., Shute, R., Varlow, M., Murrihy, R., \& Kidman, T. (2014). Predictors of teacher intervention in indirect bullying at school and outcome of a professional development presentation for teachers. Educational Psychology, 34(7). Retrieved from http://www.tandfonline. com/doi/full/10.1080/01443410.2013.785385.

[12] DM - Made for minds (2017). OECD education study reveals gender gap and strong disparity. Retrieved from https://www.dw.com/en/oecd-education-study-reveals-gendergap-and-strong-disparity/a-40462599.
[13] Fishman, G. (2015). Violence, its roots and trends. Ministry of Education in Israel. Director of Youth Company. Retrieved from: meyda.education.gov.il/ files/noar/ana31.doc

[14] Flick, U. (2018). An introduction to qualitative research. Missing place: Sage Publications Limited.

[15] Friedman, Y. (2011). School-parent relations in Israel. Studies in the Director and the Education Organization, 32, 237-267.

[16] Gaikhorst, L., Beishuizen, J. J., Korstjens, I. M., \& Volman, M. L. L. (2014). Induction of beginning teachers in urban environments: an exploration of the support structure and culture for beginning teachers at primary schools needed to improve retention of primary school teachers. Teaching and Teacher Education, 42, 23-33.

[17] Gerring, J. (2016). Case Study Research: Principles and Practices (2d ed). Boston University Department of Political Science. Retrieved from http://blogs.bu.edu/jgerring/files/2016 /01/Text_39.pdf

[18] Harel-Fisch, Y. et al., (2011). Negative school perceptions and involvement in school bullying: A universal relationship across 40 countries. Journal of Adolescence, 34(4), 639-652.

[19] Hungafu. W. (2012). Effects of EFL teachers' selfefficacy on motivational teaching behaviors. Asian Social Science, 8(15), 68-74.

[20] Kwanghyun, K., \&Soyeon, L. (2016). Psychological empowerment. Oxford Bibliographies. Retrieved from http://www.oxfordbibliographies.com/view/document/obo9780199846740/obo-9780199846740-0090.xml

[21] Lengyel, L., \& Vernon-Dotson, L. (2010). Preparing special education teacher candidates: Extending case method to practice. Teacher Education and Special Education, 33(3), 248-256.

[22] Lindqvist, H., Werulander, M., Wernerson, A., \& Thornberg, R. (2017). Resolving feelings of professional inadequacy: Student teachers' coping with distressful situations. Teaching and Teacher Education, 64, 270-279.

[23] Masats, D., \& Dooly, M. (2011). Rethinking the use of video in teacher education: A holistic approach. Teaching and Teacher Education, 27(7), 1151-1162.

[24] Seibert, S E., Wang, G., \& Courtright, S.H. (2011). Antecedents and consequences of psychological and team empowerment in organizations: A meta-analytic review. Journal of Applied Psychology 96(5), 981-1003.

[25] Sela-Shayovitz, R. (2009). Dealing with school violence: The effects of training for prevention on school violence on teachers' perceived self-efficacy in dealing with violent Events. Teaching and Teacher Education, 25, 1061-1066. 
[26] Shavit, Y., \& Blank, C. (2010). School discipline in Israel. In R. Arum, \& M. Velez (Eds.), Improving learning environments in schools: Lessons from abroad. Stanford, CA: Stanford University Press. Retrieved from: http:// taubcenter.org.il/tauborgilwp/wpcontent/uploads/School_ Discipline Research_10.03.pdf.

[27] Sprietzer, G. M. (1995). Psychological empowerment in the workplace: Construct definition, measurement, and validation. Academy of Management Journal, 25(5), 679-704.

[28] Srabstein, J. C., \& Leventhal, B. L. (2010). Prevention of bullying-related morbidity and mortality: A call for public health policies. Bulletin of the World Health Organization, 88, 403.

[29] Walter, B.F., \& Adam, M.D. (2014). Teaching communication skills: Using action methods to enhance roleplay in problem-based learning. Simulation in Healthcare, 9(4), 220-227. Retrieved from: http://journals.lww.com/ simulationinhealthcare/pages/default.aspx. 